\title{
Escitalopram tolerability as mono- versus augmentative therapy in patients with affective disorders: a naturalistic study
}

This article was published in the following Dove Press journal:

Neuropsychiatric Disease and Treatment

7 February 2013

Number of times this article has been viewed

\section{Bernardo Dell'Osso \\ Chiara Arici \\ Cristina Dobrea \\ Giulia Camuri \\ Beatrice Benatti \\ A Carlo Altamura}

University of Milan, Department of Psychiatry, Fondazione IRCSS Ca' Granda, Ospedale Maggiore Policlinico, Milano, Italy
Correspondence: Bernardo Dell'Osso Department of Psychiatry, University of Milan, Fondazione IRCCS Ca' Granda, Ospedale Maggiore Policlinico, Via F Sforza 35, 20I22, Milan, Italy

Tel +390255035994

$\mathrm{Fax}+390250320310$

Email bernardo.dellosso@unimi.it
Background: Escitalopram is a selective serotonin reuptake inhibitor, widely used in the treatment of affective disorders. The purpose of this study was to examine its safety and tolerability, as mono- versus augmentative therapy, in a group of patients with affective disorders.

Materials and methods: The sample consisted of 131 patients suffering from different affective disorders, including major depressive disorder, bipolar disorder, and generalized anxiety disorder, who received escitalopram for at least 4 weeks. Data were analyzed on the basis of mono- versus augmentative therapy, as well as age, gender, mean daily dosage, and patterns of combination therapy.

Results: Sixty-seven (51.1\%) patients were treated with monotherapy (mean dose of $11.76 \mathrm{mg} /$ day) and 64 (48.9\%) with augmentative escitalopram (mean dose of $12.81 \mathrm{mg} /$ day). The mean duration of escitalopram treatment was 14 months. The most frequently combined compounds were: other antidepressants (36.5\%), mood stabilizers (33.4\%), and atypical antipsychotics (30.1\%). Side effects were reported in 5.3\% of the total sample and the most common were insomnia (2.3\%), nausea (2.3\%), and dizziness ( $0.8 \%)$. No significant difference, in terms of tolerability, in mono- versus augmentative therapy groups was found. In addition, neither age nor gender was significantly correlated with a greater presence of side effects. Finally, no significant correlation between dosage and side effects was observed.

Conclusion: Over a 14-month observation period, escitalopram, either as monotherapy or an augmentative treatment, was found to be well tolerated in a large sample of patients with affective disorders, with an overall low rate of side effects.

Keywords: affective disorders, escitalopram, tolerability, monotherapy, augmentative therapy

\section{Introduction}

Escitalopram, a selective serotonin reuptake inhibitor (SSRI), is the $\mathrm{S}$ enantiomer of citalopram, a racemic mixture of the $\mathrm{R}$ and $\mathrm{S}$ enantiomers, in a 1:1 ratio. ${ }^{1}$ The two stereoisomers markedly differ in potency for the inhibition of neuronal serotonin uptake, with escitalopram being more potent than the R enantiomer. The S enantiomer, in fact, seems to be associated with greater antidepressant activity, whereas the $\mathrm{R}$ enantiomer has been found to compete with the $\mathrm{S}$ enantiomer on the serotonin transporters, with lower affinity. ${ }^{2}$

Escitalopram is currently approved for the treatment of major depressive disorder (MDD). In addition, in many countries of the European Union, it is indicated for the treatment of some anxiety disorders, like panic disorder, social anxiety disorder, generalized anxiety disorder (GAD), and obsessive-compulsive disorder. ${ }^{3}$ The compound 
is licensed for use at doses up to $20 \mathrm{mg}$ /day, while there are few data supporting its use at higher doses. ${ }^{4,5}$

In terms of tolerability, common side effects (incidence $\geq 5 \%$ ) of escitalopram, occurring during the first 8 weeks of treatment (and more frequently than placebo), were represented by nausea, insomnia, fatigue, diarrhea, dizziness, dry mouth, somnolence, and ejaculation failure. ${ }^{3}$ With respect to cardiovascular safety, a dose-dependent increase of QT interval and ventricular arrhythmias, including Torsade de Pointes, have been recently reported. ${ }^{6}$

Actually, the short-term side effects profile of escitalopram was found to be similar to citalopram and significantly better than venlafaxine. ${ }^{3,7}$ A limited number of patients were found to discontinue escitalopram due to side effects, although this was significantly fewer than those who discontinued when on paroxetine or venlafaxine. ${ }^{7,8}$ In general, the incidence of reported side effects tended to decrease over time, even though related withdrawals, occurring in the early stages of double-blind treatment, imply that patients, who continue with longer treatment, are likely those with good tolerability at the beginning. ${ }^{3}$ Furthermore, long-term use of escitalopram in depressive and anxiety disorders did not result in the emergence of side effects, which had not been seen during acute treatment. ${ }^{9}$

To date, despite several studies evaluating the acute and long-term tolerability of the molecule in patients with affective disorders, few data comparing the safety and tolerability of escitalopram in mono- versus augmentative therapy are available, particularly for longer observation periods. Such an issue, however, seems to be of relevant clinical importance, reflecting real clinical practice among patients with comorbid medical and psychiatric disorders, who are on concomitant polytherapies, and who are of different age groups.

Therefore, the aim of the present study is to naturalistically assess the safety and tolerability of escitalopram and related patterns of prescription (ie, main psychiatric diagnosis, medical and psychiatric comorbidities, and prescription in different age groups) in a large sample of patients with affective disorders, focusing on the comparison between mono- versus augmentative therapy.

\section{Methods}

The sample consisted of 131 outpatients attending the Mood Disorder Clinic and related community services at the Department of Psychiatry of the University of Milan between 2010 and 2011. Eligible patients were adult subjects who were diagnosed with mood and/or anxiety disorders (eg, MDD, $\mathrm{BD}$, and GAD), according to the Diagnostic and Statistical
Manual (DSM)-IV-TR criteria. ${ }^{10}$ If a comorbid disorder was present, the affective disorder had to be the primary condition (ie, causing the most significant distress and dysfunction), and it had to provide the primary motivation to seek treatment.

Diagnoses were performed by trained psychiatrists through the administration of the Structured Clinical Interview for DSM Axis I (SCID-I) ${ }^{11}$ and Axis II (SCID-II). ${ }^{12}$ The diagnostic evaluation was additionally completed in order to better quantify the severity of the disorder, with the administration of the following psychometric scales: the Hamilton Rating Scale for Depression, ${ }^{13}$ the Hamilton Anxiety Rating Scale, ${ }^{14}$ the Montgomery-Asberg Rating Scale for Depression, ${ }^{15}$ and the Clinical Global Impression scales. ${ }^{16}$

Recruited patients had to be older than 18 years, of either gender, and treated with escitalopram for at least 1 month. Escitalopram was prescribed either as sole therapy or as an augmentative agent. After obtaining patients' written informed consent, clinical and demographic variables were collected, including: age, gender, age at onset, primary diagnosis, family history for mental disorders, psychiatric and medical comorbidity, mean daily dosage and overall duration of escitalopram, combined therapy, adverse events, and side effects.

The assessment of safety and tolerability represented the primary study aim, and such aspects were assessed at each monthly visit after baseline, using spontaneously reported events and rates of discontinuation for adverse events. In addition, patients were specifically required to report the occurrence of cardiovascular symptoms such as palpitations, dizziness, syncope, or seizures developed during treatment. In such cases, a cardiac evaluation including electrocardiography (ECG) was planned in order to exclude malignant arrhythmias.

At the end of the observation period - lasting from a minimum of 4 weeks to several months - patients were divided in two groups, according to receiving either monoor augmentative therapy. Patients included in the second group were additionally divided into different subgroups based on the compound escitalopram was augmented to (eg, mood stabilizers, other antidepressants [SSRIs, serotoninnorepinephrine reuptake inhibitors, tricyclic antidepressants], typical and atypical antipsychotics), and demographic and clinical variables were compared using one-way analyses of variance for continuous variables, and $\chi^{2}$ tests for categorical ones. Post-hoc tests (Bonferroni) were additionally performed to assess between-group differences. For all the analyses, the level of statistical significance was set at 0.05 . All the statistical analyses were performed using the Statistical Package 
for the Social Sciences for Windows software (version 17.0; SPSS Inc., Chicago, Illinois, USA).

\section{Results}

The study sample consisted of 49 males (37.4\%) and 82 females (62.6\%), with a mean age of $53.8 \pm 15.16$ years and a mean age at onset of $39.25 \pm 16.2$ years. Fifty-three (40.4\%) patients were older than 60 years old. Demographic and clinical variables of the total sample are summarized in Table 1 . The most common diagnoses were MDD $(n=66$, $50.4 \%), \mathrm{BD}(\mathrm{n}=21,16 \%)$, and $\mathrm{GAD}(\mathrm{n}=12,9.2 \%)$.

Sixty-seven patients $(51.1 \%)$ received escitalopram as sole therapy (mean dosage of $11.76 \mathrm{mg} /$ day), whereas 64 patients $(48.9 \%$ ) were in the augmentation group (mean dosage of $12.81 \mathrm{mg} /$ day). The group on polytherapy had, understandably, more severe clinical features, as indicated by a longer duration of illness $(t=2.983 ; P=0.005)$ and higher rates of psychiatric comorbidity $(t=3.345 ; P=0.001)$.
The mean duration of escitalopram treatment did not differ between the two groups, ranging from 12.5 to 16 months.

Statistical analysis revealed no significant differences in terms of the escitalopram daily dosage between the monoand augmentative therapy groups.

The main associated treatments were represented by other antidepressants (36.5\%), mood stabilizers (33.4\%), and atypical antipsychotics (30.1\%). Side effects were reported in $5.3 \%$ of the total sample and included: insomnia $(2.3 \%)$, nausea $(2.3 \%)$, and dizziness $(0.8 \%)$, which were the most frequently observed ones. Statistical analysis showed no significant differences in terms of tolerability in the monotherapy group versus the augmentative therapy group. Side effects were mild and no patient had to discontinue therapy because of adverse events. No cardiovascular symptoms were reported during the study and it was not necessary to perform any ECG monitoring. Side effect rates of the total sample and the related subgroups are reported in Table 2.

Table I Demographic and clinical variables of the study sample

\begin{tabular}{|c|c|c|c|}
\hline Variables & Total sample $(n=|3|)$ & Monotherapy $(n=67)$ & Polytherapy $(n=64)$ \\
\hline \multirow[t]{2}{*}{ Gender } & Males $n=49(37.4 \%)$ & Males $=22(33 \%)$ & Males $=27(42 \%)$ \\
\hline & Females $n=82(62.6 \%)$ & Females $=45(67 \%)$ & Females $=37(58 \%)$ \\
\hline Age (years) & $53.8 \pm 15.16$ & $51.79 \pm 15.78$ & $55.94 \pm 14.29$ \\
\hline Age at onset (years) & $39.25 \pm 16.2$ & $41.46 \pm 17.33$ & $36.74 \pm 14.58$ \\
\hline Duration of illness (months) & $176.6 \pm 17 \mid .9$ & $138.11 \pm 129.32 *$ & $215.56 \pm 169.43^{*}$ \\
\hline \multicolumn{4}{|l|}{ Most common diagnoses } \\
\hline Major depressive disorder & $\mathrm{n}=66(50.4 \%)$ & $\mathrm{n}=39(58 \%)$ & $n=27(42 \%)$ \\
\hline Bipolar disorder & $\mathrm{n}=21(16 \%)$ & $\mathrm{n}=4(6 \%)$ & $\mathrm{n}=18(28 \%)$ \\
\hline Generalized anxiety disorder & $\mathrm{n}=12(9.2 \%)$ & $\mathrm{n}=8(12 \%)$ & $\mathrm{n}=4(6 \%)$ \\
\hline Family history of psychiatric disorders & $\mathrm{n}=57(43.5 \%)$ & $\mathrm{n}=33(49 \%)$ & $\mathrm{n}=46(72 \%)$ \\
\hline \multicolumn{4}{|l|}{ Psychiatric comorbidity } \\
\hline Absent & $\mathrm{n}=52(44.4 \%)$ & $\mathrm{n}=34(5 \mathrm{I} \%)^{* *}$ & $\mathrm{n}=18(28 \%)^{* *}$ \\
\hline Generalized anxiety disorder & $\mathrm{n}=21(17.9 \%)$ & $\mathrm{n}=8(\mathrm{I} 2 \%)$ & $\mathrm{n}=13(20 \%)$ \\
\hline Alcohol/substance abuse & $\mathrm{n}=18(15.4 \%)$ & $\mathrm{n}=9(13 \%)$ & $\mathrm{n}=9(14 \%)$ \\
\hline Major depressive disorder & $\mathrm{n}=8(6.8 \%)$ & $\mathrm{n}=3(4 \%)$ & $\mathrm{n}=5(8 \%)$ \\
\hline \multicolumn{4}{|l|}{ Medical comorbidity } \\
\hline Absent & $\mathrm{n}=45(40.5 \%)$ & $\mathrm{n}=27(40 \%)$ & $\mathrm{n}=18(28 \%)$ \\
\hline Hypertension & $\mathrm{n}=9(8.1 \%)$ & $\mathrm{n}=6(9 \%)$ & $\mathrm{n}=3(5 \%)$ \\
\hline Cardiovascular disorders & $\mathrm{n}=6(5.4 \%)$ & $\mathrm{n}=3(4 \%)$ & $\mathrm{n}=3(5 \%)$ \\
\hline Cancer & $\mathrm{n}=6(5.4 \%)$ & $\mathrm{n}=3(4 \%)$ & $\mathrm{n}=3(5 \%)$ \\
\hline Mean dose of escitalopram (mg) & $12.28 \pm 3.25$ & $11.76 \pm 4.58$ & $12.81 \pm 6.25$ \\
\hline \multicolumn{4}{|l|}{ Combined treatments } \\
\hline Mood stabilizers & $\mathrm{n}=19(15 \%)$ & - & $\mathrm{n}=19(30 \%)$ \\
\hline Other antidepressants & $\mathrm{n}=10(8 \%)$ & - & $\mathrm{n}=10(16 \%)$ \\
\hline Atypical antipsychotics & $\mathrm{n}=19(15 \%)$ & - & $\mathrm{n}=19(30 \%)$ \\
\hline \multicolumn{3}{|l|}{ treatment (months) } & $|2.47 \pm||.5|$ \\
\hline Side effects & $\mathrm{n}=7(5.3 \%)$ & $\mathrm{n}=4(6 \%)$ & $\mathrm{n}=3(5 \%)$ \\
\hline Insomnia & $\mathrm{n}=3(2.3 \%)$ & $\mathrm{n}=\mathrm{I}(\mathrm{I} \%)$ & $\mathrm{n}=2(3 \%)$ \\
\hline Nausea & $\mathrm{n}=3(2.3 \%)$ & $\mathrm{n}=2(3 \%)$ & $\mathrm{n}=\mathrm{I}(\mathrm{I} \%)$ \\
\hline Dizziness & $\mathrm{n}=\mathrm{I}(0.8 \%)$ & $\mathrm{n}=\mathrm{I}(\mathrm{I} \%)$ & $\mathrm{n}=0(0 \%)$ \\
\hline
\end{tabular}

Notes: *Duration of illness: $t=2.983 ; P=0.005$; **rates of psychiatric comorbidity: $t=3.345 ; P=0.00 \mathrm{I}$. Standard deviations for continuous variables and percentages for dichotomous ones are shown in brackets.

Abbreviation: $n$, number. 
Table 2 Side effect rates in the total sample and among related subgroups

\begin{tabular}{lllll}
\hline Side effects & Total sample & Monotherapy & Polytherapy & Type of combined treatment \\
& $\mathbf{n}=\mathbf{7}(\mathbf{5 . 3 \%})$ & $\mathbf{n}=\mathbf{4}(\mathbf{6} \%)$ & $\mathbf{n}=\mathbf{3}(\mathbf{5} \%)$ & $\mathbf{n = 3 ( 5 \% )}$ \\
\hline Insomnia & $\mathrm{n}=3(2.3 \%)$ & $\mathrm{n}=1(1 \%)$ & $\mathrm{n}=2(3 \%)$ & Typical antipsychotics \\
Nausea & $\mathrm{n}=3(2.3 \%)$ & $\mathrm{n}=2(3 \%)$ & $\mathrm{n}=1(1 \%)$ & TCAs \\
Dizziness & $\mathrm{n}=\mathrm{I}(0.8 \%)$ & $\mathrm{n}=\mathrm{I}(\mathrm{I} \%)$ & $\mathrm{n}=0(0 \%)$ & None \\
\hline
\end{tabular}

Abbreviations: $n$, number; TCA, tricyclic antidepressants.

The statistical analysis showed no significant correlation between side effects and age ( $\left.\mathrm{Phi}=0.150 ; \chi^{2}=0.08\right)$, combined therapy $\left(\mathrm{Phi}=0.029 ; \chi^{2}=0.74\right)$, and gender $(\mathrm{Phi}=0.04$; $\left.\chi^{2}=0.62\right)$. Furthermore, no statistically significant associations were reported between increasing dosages and the amount of side effects experienced $(t=3.21 ; P=0.08)$.

\section{Discussion}

Escitalopram was found to be well tolerated overall in a large sample of patients with affective disorders, both as a monotherapy and as augmentative treatment, as well as in older patients. In fact, a minor rate of subjects (5.3\%) showed side effects, with insomnia, nausea, and dizziness being the most common ones. Side effects were mild and transient, and no discontinuation of therapy due to tolerability issues occurred in the sample over the whole observation period. From this perspective, the reported results seem to be of particular clinical interest given that, on average, the duration of treatment lasted more than 1 year in the whole sample and across the related subgroups.

The cardiovascular safety of escitalopram is an important issue to consider. Recent data from the literature showed that escitalopram may affect the QTc interval, likely through a dosedependent mechanism. ${ }^{17}$ Recently, Hanash et a $1{ }^{18}$ examined the CV safety of 1-year of treatment with escitalopram, compared with placebo, in patients with recent acute coronary syndrome, supporting the safety and favorability profile of the compound in such patients. In the present study, no cardiovascular side effects were reported, even though it needs to be specified that the study methods did not include routine ECG monitoring.

In clinical practice, augmentative and combination therapies are considered valid strategies to treat partial response or lack of response to antidepressant monotherapy, even though such an approach may lead to an increase in side effects, adverse effects, drug interactions and, ultimately, reduced compliance. ${ }^{19}$

Data from the present study seem to suggest that escitalopram may be safely used in combination with other compounds (eg, mood stabilizers, other antidepressants, and antipsychotics). On the one hand, such results may not support what is generally observed in clinical practice, with combined treatments resulting in higher frequency of side effects when compared to monotherapies. On the other hand, they seem to support a particularly favorable tolerability for selective antidepressants, like escitalopram. Present findings are, moreover, consistent with a recent meta-analysis of Rocha et al, ${ }^{20}$ who reviewed studies assessing the effect of the combination of antidepressants in MDD. Mirtazapine plus SSRIs, and tricyclic antidepressants plus SSRIs resulted in superior effects than SSRIs alone in obtaining remission, or achieving both remission and response, respectively. Consistently with the present report, the authors did not find any difference between the combined and monotherapy groups in terms of drop-out rates due to adverse effects. Such results were seen as supportive of the greater efficacy of antidepressant combinations versus monotherapies, with no significant decrease in tolerability ${ }^{20}$ However, it needs to be specified that the review by Rocha et $\mathrm{a}^{20}$ solely focused on the acute treatment of MDD and, moreover, on the combination of antidepressants, whereas our sample included patients with additional diagnoses as well, using different psychotropic compounds in their therapeutic regimen.

Other studies have assessed the long-term efficacy and tolerability of combination treatments. Rush et al, ${ }^{21}$ for instance, compared two antidepressant combinations with SSRI monotherapy to determine whether combination treatment produced higher remission rates in the acute phase (12 weeks) and after long-term treatment (7 months). Of note, they found that no combination therapy outperformed monotherapy. Moreover, the authors found that some combinations (eg, extendedrelease venlafaxine plus mirtazapine, versus escitalopram plus placebo) may bring a higher risk of side effects. ${ }^{21}$

In the present study, the statistical analysis showed that age did not correlate with the presence of side effects. Such findings seem to be of clinical relevance, suggesting that the molecule might be used in the elderly without any additional specific concerns within the recommended therapeutic range. In addition, gender did not significantly correlate with side effects, suggesting the absence of gender-specific differences in the pharmacodynamic and pharmacokinetic profiles of the compound. 
Finally, the absence of a significant correlation between dosage and side effects seems to support a favorable tolerability profile for the molecule, which is consistent with the available literature. ${ }^{5,22,23}$ From this perspective, Wade et $\mathrm{al}^{5}$ conducted an open-label, pilot study to investigate the efficacy, safety, and tolerability of escitalopram in doses up to $50 \mathrm{mg}$ in MDD. In this study, doses up to $40 \mathrm{mg}$ were generally well tolerated, whereas higher doses were more poorly tolerated. Furthermore, no unexpected safety issues arose from the use of higher doses, with only minor weight gain being observed, which did not appear to be dose related. ${ }^{5}$

In conclusion, the present study showed escitalopram to be safe and well tolerated in a large sample of patients with affective disorders, used either as sole or combination therapy, both in young and elderly people. The study was conducted with an open design and without a randomization process or a control group, so further long-term, double-blind randomized controlled studies are necessary to confirm the present results.

\section{Disclosure}

The authors report no conflicts of interest in this work. Dr Dell'Osso has been part of the Speaker Bureau of Astra Zeneca, Bristol Myers Squibb, Janssen-Cilag, Eli Lilly, Pfizer, Glaxo Smith Kline, Lundbeck, Cyberonics, and Italfarmaco. Professor Altamura is a consultant for Roche, Merck, Astra Zeneca, Bristol Myers Squibb, Janssen-Cilag, Lundbeck, Sanofi, Eli Lilly and Pfizer. For the remaining authors, there are no conflicts of interest.

\section{References}

1. Kasper S, Sacher J, Klein N, et al. Differences in the dynamics of serotonin reuptake transporter occupancy may explain superior clinical efficacy of escitalopram versus citalopram. Int Clin Psychopharmacol. 2009;24(3):119-125.

2. Jacquot C, David DJ, Gardier AM, Sánchez C. Escitalopram and citalopram: the unexpected role of the R-enantiomer. Encephale. 2007;33(2): 179-187. French.

3. Baldwin DS, Reines EH, Guiton C, Weiller E. Escitalopram therapy for major depression and anxiety disorders. Ann Pharmacother. 2007;41(10): $1583-1592$.

4. Rabinowitz I, Baruch Y, Barak Y. High-dose escitalopram for the treatment of obsessive-compulsive disorder. Int Clin Psychopharmacol. 2008; 23(1):49-53.
5. Wade AG, Crawford GM, Yellowlees A. Efficacy, safety and tolerability of escitalopram in doses up to $50 \mathrm{mg}$ in Major Depressive Disorder (MDD): an open-label, pilot study. BMC Psychiatry. 2011;11:42.

6. Waring WS. Clinical use of antidepressant therapy and associated cardiovascular risk. Drug Healthc Patient Saf. 2012;4:93-101.

7. Garnock-Jones KP, McCormack PL. Escitalopram: a review of its use in the management of major depressive disorder in adults. CNS Drugs. 2010;24(9):769-796.

8. Baldwin DS, Cooper JA, Huusom AK, Hindmarch I. A double-blind, randomized, parallel-group, flexible-dose study to evaluate the tolerability, efficacy and effects of treatment discontinuation with escitalopram and paroxetine in patients with major depressive disorder. Int Clin Psychopharmacol. 2006;21(3):159-169.

9. Kasper S, Lemming OM, de Swart H. Escitalopram in the longterm treatment of major depressive disorder in elderly patients. Neuropsychobiology. 2006;54(3):152-159.

10. American Psychiatric Association. Diagnostic and Statistical Manual of Mental Disorders. Text Revision, 4th ed. Washington DC: American Psychiatric Association; 2000

11. First MB, Spitzer R, Gibbon M, Williams JBW. Structured Clinical Interview for DSM-IV-TR Axis I Disorders, Research Version, Patient Edition $(S C I D-I / P)$. New York: Biometrics Research, New York State Psychiatric Institute; 2002.

12. First MB, Gibbon M, Spitzer RL, Williams JBW, Benjamin LS Structured Clinical Interview for DSM-IV Axis II Personality Disorders (SCID-II). Washington DC: American Psychiatric Press; 1997.

13. Hamilton M. A rating scale for depression. J Neurol Neurosurg Psychiatry. 1960;23:56-62.

14. Hamilton M. The assessment of anxiety states by rating. $\mathrm{Br} J \mathrm{Med}$ Psychol. 1959;32(1):50-55.

15. Montgomery SA, Asberg M. A new depression scale designed to be sensitive to change. Br J Psychiatry. 1979;134:382-389.

16. Guy W. Clinical global impressions. In: ECDEU Assessment Manual for Psychopharmacology. Revised. Rockville, MD: US Department of Health and Human Services; 1976:218-222.

17. Howland RH. A question about the potential cardiac toxicity of escitalopram. J Psychosoc Nurs Ment Health Serv. 2012;50(4):17-20.

18. Hanash JA, Hansen BH, Hansen JF, Nielsen OW, Rasmussen A, Birket-Smith M. Cardiovascular safety of one-year escitalopram therapy in clinically nondepressed patients with acute coronary syndrome: results from the DEpression in patients with coronary Artery Disease (DECARD) trial. J Cardiovasc Pharmacol. 2012;60(4):397-405.

19. Cadieux RJ. Practical management of treatment-resistant depression. Am Fam Physician. 1998;58(9):2059-2062.

20. Rocha FL, Fuzikawa C, Riera R, Hara C. Combination of antidepressants in the treatment of major depressive disorder: a systematic review and meta-analysis. J Clin Psychopharmacol. 2012;32(2):278-281.

21. Rush AJ, Trivedi MH, Stewart JW, et al. Combining medications to enhance depression outcomes (CO-MED): acute and long-term outcomes of a single-blind randomized study. Am J Psychiatry. 2011; 168(7):689-701.

22. Reis M, Chermá MD, Carlsson B, Bengtsson F; Task Force for TDM of Escitalopram in Sweden. Therapeutic drug monitoring of escitalopram in an outpatient setting. Ther Drug Monit. 2007;29(6):758-766.

23. Höschl C, Svestka J. Escitalopram for the treatment of major depression and anxiety disorders. Expert Rev Neurother. 2008;8(4):537-552.
Neuropsychiatric Disease and Treatment

\section{Publish your work in this journal}

Neuropsychiatric Disease and Treatment is an international, peerreviewed journal of clinical therapeutics and pharmacology focusing on concise rapid reporting of clinical or pre-clinical studies on a range of neuropsychiatric and neurological disorders. This journa is indexed on PubMed Central, the 'PsycINFO' database and CAS

\section{Dovepress}

The manuscript management system is completely online and includes a very quick and fair peer-review system, which is all easy to use. Visit http://www.dovepress.com/testimonials.php to read real quotes from published authors. 